\title{
Measurement errors on sediment concentration from traditional runoff collection tanks and its correction possibility
}

\author{
Yuhan Huang ${ }^{1}$, Hui Zhao ${ }^{2}$, Fahu Li ${ }^{1 *}$, Pujin Yuan ${ }^{2}$, Wei Wang ${ }^{3}$, Guanghui Zhang ${ }^{4}$ \\ (1. College of Water Resources and Civil Engineering, China Agricultural University, Beijing 100083, China; \\ 2. Monitoring Center of Soil and Water Conservation, Ministry of Water Resources, Beijing 100053, China; \\ 3. College of Engineering, China Agricultural University, Beijing 100083, China; \\ 4. Faculty of Geographical Science, Beijing Normal University, Beijing 100875, China)
}

\begin{abstract}
Runoff plots are widely used worldwide to monitor water and soil losses. Sediment concentration in runoff collection tank is measured by stirring-sampling procedure, but this method may produce high measurement error due to the uneven mixing of collected sediments with water and soil particle deposition. This study aimed to identify the relationship between actual and measured sediment concentrations, so as to estimate the systematic error of sediment concentration measurement from runoff collection tank by traditional stirring-sampling procedure and the possibility to eliminate it. Four major soils including black soil, silt loess, clay loess, and purple soil in China were used to determine the correlation between the measured and designed sediment concentrations in laboratory. Tested sediment concentration was 1, 2, 5, 8, 10, 20, 50, 80, $100,200,500,800$, and $1000 \mathrm{~kg} / \mathrm{m}^{3}$, and total sediment-laden water volume was $50 \mathrm{~L}$ and $100 \mathrm{~L}$. Five samples were collected successively from collection tank for each treatment and their sediment concentrations were measured by conventional oven-drying method. The results showed that all the measured sediment concentration values were smaller than the designed ones, but both the measured and designed values were linearly correlated significantly with determination coefficients greater than 0.8 , generally. In the whole tested concentration range, the systematical error was -0.19 to $-319.95 \mathrm{~kg} / \mathrm{m}^{3}$ and relative error was $0.30 \%-84.5 \%$ for the 4 tested soils and 2 total sediment-laden water volumes. These results indicated a necessity and possibility to correct conventional sediment concentration measurement value. The result is usable to assess and correct the measurement error of sediment concentrations from traditional runoff plot.
\end{abstract}

Keywords: collection tank, measurement error, runoff plot, sediment concentration, stirring-sampling method DOI: $10.25165 /$ j.ijabe.20191203.4208

Citation: Huang Y H, Zhao H, Li F H, Yuan P J, Wang W, Zhang G H. Measurement errors on sediment concentration from traditional runoff collection tanks and its correction possibility. Int J Agric \& Biol Eng, 2019; 12(3): 77-83.

\section{Introduction}

Runoff plots with a standard size or varied sizes are widely used for the measurement of runoff and its sediment concentration to aid soil erosion research and the effectiveness evaluation of soil and water conservation measurement ${ }^{[1,2]}$. From the first runoff plot built by a German pedologist in 1877, a lot of field observation stations have been set up in the world to investigate the effects of soil, slope gradient, vegetation coverage, and crop type and its rotation on soil erosion ${ }^{[3-5]}$. There were about 152 water and soil conservation field stations and more than 6000 runoff plots built in China for routine long-term fixed observation ${ }^{[6]}$. Runoff plot has been a basic and important facility to monitor soil erosion in different regions. Based on the systematical analyses of 30-year observation data from a number of runoff plots in 30 states of USA,

\section{Received date: 2018-03-04 Accepted date: 2019-04-22}

Biographies: Yuhan Huang, $\mathrm{PhD}$, research interest: soil erosion, Email: huangyuhan0710@foxmail.com; Hui Zhao, PhD, Professoriate Senior Engineer, research interest: soil and water conservation monitoring, Email: 7166zhaohui@ 163.com; Pujin Yuan, Master, Senior Engineer, research interest: soil and water conservation monitoring, Email: yuanpujin@163.com; Wei Wang, PhD, Associate Professor, research interest: agricultural water-soil engineering, Email: weiwang@cau.edu.cn; Guanghui Zhang, PhD, Professor, research interest: soil erosion and soil and water conservation, Email: ghzhang@bnu.edu.cn.

*Corresponding author: Fahu Li, PhD, Professor, research interest: soil physics and soil erosion. College of Water Resources \& Civil Engineering, China Agricultural University, Beijing 100083, China. Tel: +86-10-62737706, Fax: +86-10-62737796, Email: lifahu@ cau.edu.cn.
Wischmeier and Smiths developed a well-known empirical soil erosion prediction model ${ }^{[7]}$, i.e., the Universal Soil Loss Equation (USLE), and runoff plot was the basic instrument to obtain the local specific parameter values required in USLE approach ${ }^{[8]}$.

Collection tank is a basic component of runoff plot. During individual rainfall-runoff event, all runoff and sediment produced from runoff plot are harvested by collection tank or container. Therefore, it is very important and necessary to accurately measure sediment concentration in collection tank $\mathrm{k}^{[9,10]}$. Stirring-sampling method is a traditional measurement method for sediment concentration in collection tank in the past more than one century ${ }^{[11-13]}$. The sediment-laden water is sampled from collection tank and then oven-dried to measure sediment concentration after it is thoroughly stirred and mixed within the collection $\operatorname{tank}^{[14,15]}$.

Due to intensive labor and high homogeneous mixing required in the measurement process, many scientists were tried to develop new sample collector or sampling technique of traditional stirring-sampling method to improve the measurement accuracy of sediment concentration in collection tank in past decades ${ }^{[16-18]}$. Kinnell ${ }^{[19]}$ tested the effects of different volumes of container to collect runoff on sediment concentration measurement accuracy. Small volume sample such as using a bottle to sample sediment-laden water ${ }^{[20,21]}$ or other techniques to control sample volume ${ }^{[22-24]}$ also developed. Xu et al. ${ }^{[25]}$ presented a precipitation sampling method, but it was time-consuming and may fail in successive rainfall events. Ye et al. ${ }^{[16]}$ developed a full profile 
sampler that was consisted of sampling pipe, outside grip, retaining ring, and chassis. Although lots of attempts have been investigated to accurately measure sediment concentration by improving traditional sampling procedure, rapid, low labor, and full-time monitoring and accurate sampling technique does not exist yet for the traditional runoff plot method.

Bagarello and Ferro ${ }^{[22]}$ investigated the effects of mixing and sampling procedure, sedimentation concentration, and collection tank volume on the measurement accuracy of sediment concentrations for a designed sediment concentration range of $5-173 \mathrm{~kg} / \mathrm{m}^{3}$. Combining with the measured results of basic and improved stirring-sampling procedures, the measurement error of sediment concentrations in collection tank was investigated. The experimental results of Lang $^{[20]}$ indicated that measurement errors were $45 \%$ and $73 \%$ respectively for bottle and pipette samplers when the designed sediment concentrations ranged from 1 to $187 \mathrm{~kg} / \mathrm{m}^{3}$. Zobisch et al. ${ }^{[26]}$ showed an error range of $4.7 \%-83 \%$ with the mean value of $41.3 \%$ for the designed sediment concentrations of $10-100 \mathrm{~kg} / \mathrm{m}^{3}$. Ciesiolka et al. ${ }^{[27]}$ tested the measurement error of sediment concentration at $20 \mathrm{~kg} / \mathrm{m}^{3}$ and found it was $18 \%-85 \%$. The results of this research generally demonstrated a measured sediment concentration was significantly lower than its designed value ${ }^{[17,20,22,26]}$ especially with a noticeable variability along the vertical direction in the collection $\operatorname{tank}^{[18]}$. However, a good linear correlation existed between the measured and designed values under the given sediment concentration range $e^{[20,22]}$, which may indicate it is possible to correct the measured data. Ciesiolka et al. ${ }^{[27]}$ suggested a method to correct the effects of sediment sinking/deposition on measured sediment concentration due to the delay of sampling time, but the measurement error after corrected was still as high as 6\%-66\%.

Stirring method is still the most widely used technique to measure sediment concentration in runoff collection tank in the world. Although sampling error has been qualitatively analyzed by some scientists, no attempt was made to systematically investigate the measurement error for the full range of possible sediment concentrations, and the error under high sediment concentrations is still unclear. The highest sediment concentration maybe reaches as high as about $1000 \mathrm{~kg} / \mathrm{m}^{3}$ in erosion-prone soil areas under special rainfall conditions ${ }^{[28,29]}$, but the investigated value in the existed researches is much lower than this possible maximum. Therefore, it is of great importance to evaluate the measurement error of traditional stirring-sampling method for the full range of possible sediment concentrations for various soil types and its correction possibility, so as to provide a reliable basic data for soil erosion research

The full range of possible sediment concentrations for four representative soils in China were collected and tested for their measurement errors according to traditional stirring-sampling procedures in runoff collection tank in this study. The aims is to: 1) determine the measurement errors of traditional stirring-sampling method on sediment concentrations for full possible sediment concentration range; 2) analyze possible error sources and establish the relationship between the measurement sediment concentration and its actual one; and 3) suggest a method or procedure to correct the measurement error of the conventional stirring-sampling method in runoff collection tank for the sediment concentration range of $1-1000 \mathrm{~kg} / \mathrm{m}^{3}$.

\section{Materials and method}

A series of laboratory experiments were designed to imitate the harvested sediment-laden runoff water before it was sampled according to traditional procedures outlined in the national standards ${ }^{[30]}$. Sediment concentration was measured by oven-drying method at $105^{\circ} \mathrm{C}$, and measurement errors were calculated.

\subsection{Experimental materials}

Four typical soils, namely, black soil from northeastern China, purple soil from southwestern China, and clay and loam loess soils from northwestern China were tested. The collected soils were air-dried before crushing and passing through a $2 \mathrm{~mm}$ sieve, and their particle size distributions were measured (Table 1) and these soils were all silt loam. The experiments were conducted at State Key Laboratory of Soil Erosion and Dryland Farming on the Loess Plateau, Institute of Soil and Water Conservation, Chinese Academy of Sciences and Ministry of Water Resources, Yangling, Shanxi Province.

Table 1 Particle size distribution of four tested soils

\begin{tabular}{cccc}
\hline Soil type & $\begin{array}{c}\text { Sand }(0.05-2 \mathrm{~mm}) \\
1 \%\end{array}$ & $\begin{array}{c}\text { Silt }(0.002-0.05 \mathrm{~mm}) \\
1 \%\end{array}$ & $\begin{array}{c}\text { Clay }(<0.002 \mathrm{~mm}) \\
1 \%\end{array}$ \\
\hline Black soil & 14.1 & 63.9 & 22.0 \\
Silt loess & 21.6 & 63.9 & 14.5 \\
Clay loess & 7.4 & 65.7 & 26.9 \\
Purple soil & 21.7 & 51.4 & 26.9 \\
\hline
\end{tabular}

\subsection{Experimental design}

The prepared soils were weighed and uniformly mixed with a given water volume to make up all possible sediment concentrations found in field conditions in the runoff collection tank. The designed sediment concentrations were $1,2,5,8,10$, $20,50,80,100,200,500,800$ and $1000 \mathrm{~kg} / \mathrm{m}^{3}$, respectively. Circular plastic bucket with an approximate $150 \mathrm{~L}$ volume was used to simulate the collection tank. The top and the bottom diameters of the plastic bucket respectively were $60 \mathrm{~cm}$ and $45 \mathrm{~cm}$, and its height was $75 \mathrm{~cm}$. Two sediment-laden runoff volumes of $50 \mathrm{~L}$ and $100 \mathrm{~L}$ were tested. All experimental treatments were repeated thrice.

\subsection{Sample preparation}

Based on the designed sediment concentrations and total volumes of sediment-laden runoff, the required sediment and water masses were calculated out and listed in Table 2. The particle density of four soils was supposed as $2.65 \mathrm{~g} / \mathrm{cm}^{3}$, and water density was $1.0 \mathrm{~g} / \mathrm{cm}^{3}$. The moisture content of air-dried soil was about $2 \%$ for purple and loess soils, and it was $1 \%$ for black and clay loess soils.

The calculated sediment mass shown in Table 2 was sieved in a bucket with a $2 \mathrm{~mm}$ mesh sieve submerged in water (Figure 1) to simulate the process of detached sediments by runoff, and then water was gradually put into the bucket to the calculated mass. The prepared sediment-laden runoff was left to stand for more than $24 \mathrm{~h}$ to imitate runoff collection process in field condition.

\subsection{Sampling and measuring procedures}

Stirring and sampling of sediment-laden water were performed according to traditional procedures (Figure 2). Empty steel cups with a volume of $500 \mathrm{~mL}$ were weighed, recorded, and labeled before sampling. Sampling was collected in about 15-20 cm depth of the bucket. Five sediment samples were taken successively for each experimental treatment, and then they were weighed and recorded again. The collected samples in the cups were precipitated at rest for $24 \mathrm{~h}$ before their supernatants were spilled over, and the left sediment residues were dried out at $105^{\circ} \mathrm{C}$ for $24 \mathrm{~h}$. The sediment concentration of samples was calculated 
according to its masses of water and dried sediment.

Table 2 Designed sediment concentrations with given water and sediment masses

\begin{tabular}{|c|c|c|c|c|c|c|c|c|c|}
\hline$V_{t} / \mathrm{L}$ & $\begin{array}{c}C_{0} \\
\mathrm{lkg} \cdot \mathrm{m}^{-3}\end{array}$ & $V_{s} / \mathrm{L}$ & $V_{u} / \mathrm{L}$ & $S / \mathrm{kg}$ & $V_{t} / \mathrm{L}$ & $\begin{array}{c}C_{0} \\
/ \mathrm{kg} \cdot \mathrm{m}^{-3}\end{array}$ & $V_{s} / \mathrm{L}$ & $V_{w} / \mathrm{L}$ & $S / \mathrm{kg}$ \\
\hline \multirow{13}{*}{50} & 1 & 0.02 & 49.98 & 0.05 & \multirow{13}{*}{100} & 1 & 0.04 & 99.96 & 0.10 \\
\hline & 2 & 0.04 & 49.96 & 0.10 & & 2 & 0.08 & 99.92 & 0.20 \\
\hline & 5 & 0.09 & 49.91 & 0.25 & & 5 & 0.19 & 99.81 & 0.51 \\
\hline & 8 & 0.15 & 49.85 & 0.41 & & 8 & 0.30 & 99.7 & 0.82 \\
\hline & 10 & 0.19 & 49.81 & 0.51 & & 10 & 0.38 & 99.62 & 1.02 \\
\hline & 20 & 0.38 & 49.62 & 1.02 & & 20 & 0.75 & 99.25 & 2.04 \\
\hline & 50 & 0.94 & 49.06 & 2.55 & & 50 & 1.89 & 98.11 & 5.10 \\
\hline & 80 & 1.51 & 48.49 & 4.08 & & 80 & 3.02 & 96.98 & 8.15 \\
\hline & 100 & 1.89 & 48.11 & 5.10 & & 100 & 3.77 & 96.23 & 10.19 \\
\hline & 200 & 3.77 & 46.23 & 10.19 & & 200 & 7.55 & 92.45 & 20.38 \\
\hline & 500 & 9.43 & 40.57 & 25.48 & & 500 & 18.87 & 81.13 & 50.96 \\
\hline & 800 & 15.09 & 34.91 & 40.77 & & 800 & 30.19 & 69.81 & 81.53 \\
\hline & 1000 & 18.87 & 31.13 & 50.96 & & 1000 & 37.74 & 62.26 & 101.92 \\
\hline
\end{tabular}

Note: $V_{t}$ is total of sediment-laden runoff volume, $\mathrm{L} ; C_{0}$ is the designed sediment concentration, $\mathrm{kg} / \mathrm{m}^{3} ; V_{s}$ is sediment volume, $\mathrm{L} ; V_{w}$ is water volume, $\mathrm{L} ; S$ is sediment mass required for the designed concentration, $\mathrm{kg}$
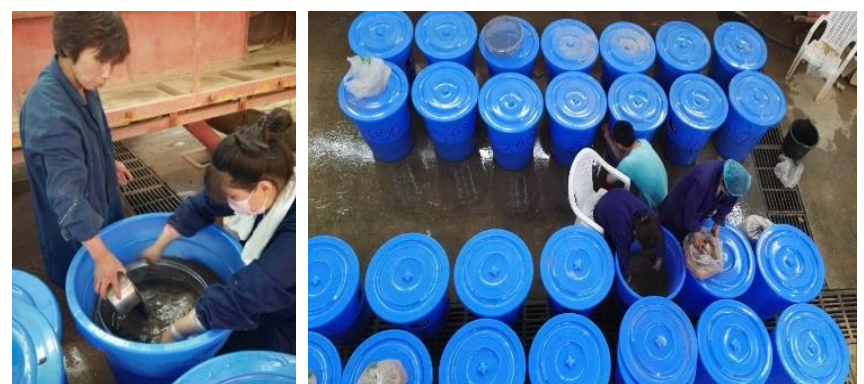

Figure 1 Sample preparation of sediment-laden runoff in the experiment

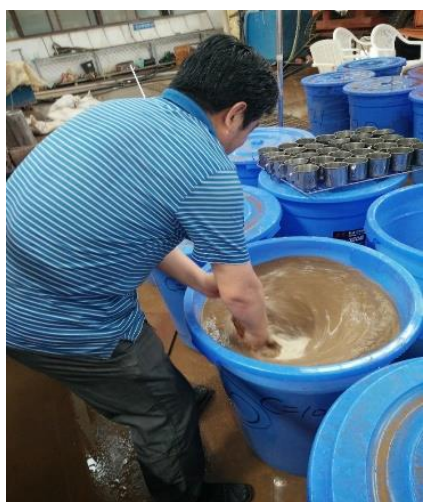

Figure 2 Stirring and sampling processes in the experiment

\subsection{Measurement error calculation}

Sediment concentration in collection tank was calculated as follows:

$$
\begin{gathered}
C=\frac{M_{\mathrm{s}}}{V} \\
M_{\mathrm{s}}=M_{\mathrm{sc}}-M_{\mathrm{c}} \\
V=\left[\left(M_{\mathrm{swc}}-M_{\mathrm{sc}}\right) / 1+\left(M_{\mathrm{sc}}-M_{\mathrm{c}}\right) / 2.65\right] \times 10^{-3}
\end{gathered}
$$

where, $C$ denotes the measured sediment concentration, $\mathrm{kg} / \mathrm{m}^{3}$; $M_{\mathrm{S}}$ refers to the mass of sediments in sample, $\mathrm{g} ; V$ represents the sample volume of sediment-water mixture, $\mathrm{L} ; M_{\mathrm{swc}}$ denotes the mass of water, sediment, and empty cup, g; $M_{\mathrm{sc}}$ stands for the mass of dried sediment and empty cup, $\mathrm{g} ; M_{\mathrm{c}}$ refers to the mass of empty cup, g.
The systematic error refers to the difference between the average measured value and its true one following infinite repeatability under the same condition, and it is mainly caused by the imperfection of measuring methods or equipment, and the change of measuring environment, etc. The relative error is generally regarded as an error parameter that can better reflect the reliability of measurement. The systematic error and the relative error between the designed and measured sediment concentrations were calculated using the following equations:

$$
\begin{gathered}
\mu=\bar{C}-C_{0} \\
\delta=\frac{\left|\bar{C}-C_{0}\right|}{C_{0}} \times 100 \%
\end{gathered}
$$

where, $\mu$ refers to systemic error, $\mathrm{kg} / \mathrm{m}^{3} ; \bar{C}$ and $C_{0}$ respectively represent the mean value of measured sediment concentrations and the designed sediment concentration, $\mathrm{kg} / \mathrm{m}^{3} ; \delta$ denotes relative error, $\%$.

Negative $\mu$ means the mean measured value of sediment concentrations smaller than its designed value, otherwise, the measured sediment concentration is greater than its designed value.

\section{Results}

\subsection{Comparison of the measured sediment concentrations with the designed values}

In the whole tested range of sediment concentrations, the measurement errors in different concentration ranges were different (data not shown). For the convenience of analysis, the sediment concentrations for each soil were divided into 3 groups, that is, low concentration group of $1-50 \mathrm{~kg} / \mathrm{m}^{3}$, and high concentration group of $50-200 \mathrm{~kg} / \mathrm{m}^{3}$, and extremely high concentration group of 200$1000 \mathrm{~kg} / \mathrm{m}^{3}$. For each concentration group, a linear fitted equation between the measured and designed sediment concentrations was applied to express their relationship as:

$$
y=a x
$$

where, $x$ and $y$ denote the measured and designed sediment concentrations, respectively, $\mathrm{kg} / \mathrm{m}^{3} ; a$ denotes the proportional coefficient between the measured and designed sediment concentrations, dimensionless.

\subsubsection{Low concentration group}

The measured and designed sediment concentrations were presented in Figure 3 for the low concentration group of $1-50 \mathrm{~kg} / \mathrm{m}^{3}$. The measured sediment concentration was linearly and significantly correlated with its designed value at the 0.01 level of statistical probability, but all the measured values following traditional stirring-sampling method were considerably smaller than the designed one. Total sediment-laden water volume affected the systematic error of measurement, and a bigger total volume generally resulted in a smaller measurement value of sediment concentration (Figure 3). In additions, soil type also affected the measurement result of sediment concentration, and the systematic error was greatest for black soil and it was smallest for silt loam in the four tested soils. The result indicates a systematic error existed when the traditional stirring-sampling method was used.

The determination coefficient $\left(R^{2}\right)$ in the low sediment concentration group was greater than 0.94 for all four tested soils (Figure 3), therefore a significant linear relationship between the measured and designed sediment concentrations in the low sediment concentration group existed at 0.01 level of statistical probability, which indicates a possibility to correct measurement error. The coefficient $a$ of fitted linear equations between the 
measured and the designed sediment concentrations was ranged from 0.22 to 0.72 in the low sediment concentration group for four tested soils. It was $0.30,0.71,0.64$, and 0.60 respectively for black soil, silt loess, clay loess, and purple soil when total volume of sediment-laden water was $50 \mathrm{~L}$ (Figure $3 \mathrm{a}$ ), and the corresponding value respectively was $0.22,0.72,0.51$, and 0.55 when the volume was $100 \mathrm{~L}$ (Figure 3b), which indicates the effects of soil type and sediment-laden water volume on the systematic error of traditional stirring-sampling method. In the low sediment concentration group, the systematic errors were -0.48 to $-34.22 \mathrm{~kg} / \mathrm{m}^{3},-0.19$ to $-13.64 \mathrm{~kg} / \mathrm{m}^{3},-0.30$ to $-16.52 \mathrm{~kg} / \mathrm{m}^{3}$, and -0.41 to $-18.93 \mathrm{~kg} / \mathrm{m}^{3}$ respectively for black soil, silt loess, clay loess, and purple soil under the total volume of sediment-laden water of $50 \mathrm{~L}$, and their corresponding values were -0.49 to $-38.42 \mathrm{~kg} / \mathrm{m}^{3},-0.57$ to $-12.34 \mathrm{~kg} / \mathrm{m}^{3},-0.36$ to $-22.52 \mathrm{~kg} / \mathrm{m}^{3}$, and -0.32 to $-19.90 \mathrm{~kg} / \mathrm{m}^{3}$ under the total volume of sediment-laden water of $100 \mathrm{~L}$, respectively.

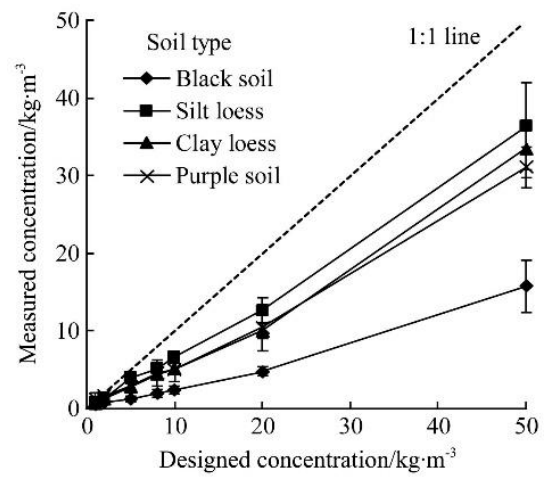

a. $50 \mathrm{~L}$

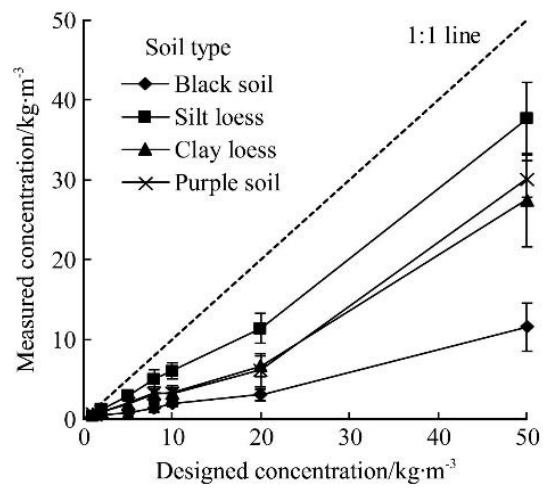

b. $100 \mathrm{~L}$

Figure 3 Comparison of the measured with the designed sediment concentrations in the low sediment concentration group of 1-50 $\mathrm{kg} / \mathrm{m}^{3}$ for four tested soils under total sediment-laden water volume of $50 \mathrm{~L}$ and $100 \mathrm{~L}$

\subsubsection{High concentration group}

Similar to that in the low sediment concentration group, there was a significant linear relationship $\left(R^{2} \geq 0.89\right)$ between the measured and its designed sediment concentration for the high sediment concentration group of $50-200 \mathrm{~kg} / \mathrm{m}^{3}$, except a case with the determination coefficient of 0.56 (Figure 4), but the systematic error was greater than that for the low one (Figures 3 and 4). The coefficient $a$ in fitted linear equation was $0.36,0.79,0.63$, and 0.69 respectively for black soil, silt loess, clay loess, and purple soil when the total volume of sediment-laden water was $50 \mathrm{~L}$ (Figure 4 a), and its corresponding value was $0.23,0.53,0.66$, and 0.66 when the total volume of sediment-laden water was $100 \mathrm{~L}$ (Figure $4 b)$. These data indicate that the measured concentrations were significantly smaller than their designed values. The systematic error of black soil was greatest in all four tested soils, and that of other soils was similar to each other. Like that in the low concentration group, the bigger volume of sediment-laden water generally resulted in a smaller measurement value (Figure 4). The systematic errors in the high sediment concentration group were -34.22 to $-129.80 \mathrm{~kg} / \mathrm{m}^{3},-13.64$ to $-35.83 \mathrm{~kg} / \mathrm{m}^{3},-16.52$ to $-85.01 \mathrm{~kg} / \mathrm{m}^{3}$, and -18.93 to $-58.42 \mathrm{~kg} / \mathrm{m}^{3}$ respectively for black soil, silt loess, clay loess, and purple soil under the total volume of sediment-laden water of $50 \mathrm{~L}$, and their corresponding values were -38.42 to $-156.90 \mathrm{~kg} / \mathrm{m}^{3},-12.34$ to $-106.66 \mathrm{~kg} / \mathrm{m}^{3},-22.52$ to $-65.26 \mathrm{~kg} / \mathrm{m}^{3}$, and -19.90 to $-69.44 \mathrm{~kg} / \mathrm{m}^{3}$ under the total volume of sediment-laden water of $100 \mathrm{~L}$, respectively.

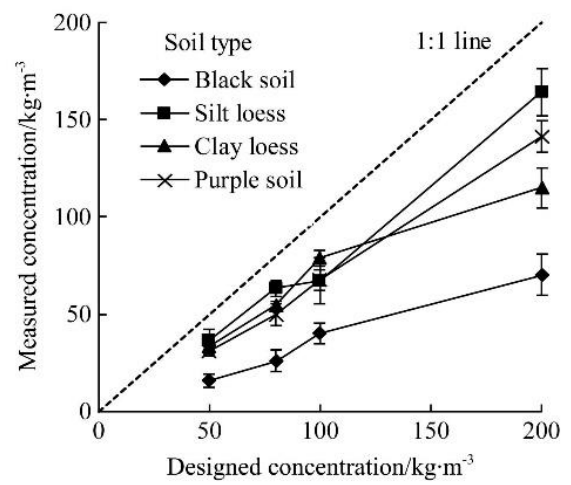

a. $50 \mathrm{~L}$

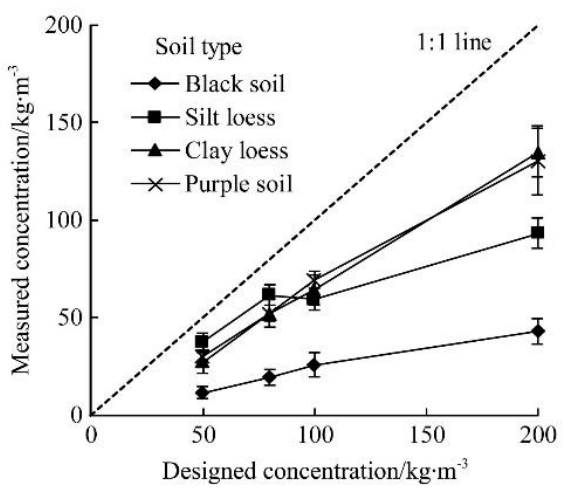

b. $100 \mathrm{~L}$

Figure 4 Comparison of the measured with the designed sediment concentrations in the high concentration group of $50-200 \mathrm{~kg} / \mathrm{m}^{3}$ for four tested soils under total sediment-laden water volume of $50 \mathrm{~L}$ and $100 \mathrm{~L}$

\subsubsection{Extremely high concentration group}

The measured values and their designed sediment concentrations in the extremely high sediment group of 200$1000 \mathrm{~kg} / \mathrm{m}^{3}$ are presented in Figure 5 for four tested soils. Figure 5 indicates that measured sediment concentrations are always smaller than the designed sediment ones in the extremely high sediment group. Similarly, the measured values of black soil are all less considerably lower than those of other soil types.

There was a linear correlation between the measured and designed sediment concentrations significantly at 0.01 level of statistical probability at the determination coefficient greater than 0.86 . The coefficient $a$ in the fitted linear equation was $0.79,0.98$, 0.96 , and 0.93 respectively for black soil, silt loess, clay loess, and purple soil when the total sediment-laden water volume was $50 \mathrm{~L}$ (Figure 5a), and its corresponding value was $0.76,0.86,0.94$, and 0.91 when the water volume was $100 \mathrm{~L}$ (Figure 5b). These coefficient values were bigger than those in the high sediment concentration group, which means the systematic error for sediment concentration measurement was smaller in the high 
concentration group than that in the extremely high concentration group (Figures 4 and 5). The systematic errors in the extremely high sediment concentration group were -117.26 to $-313.57 \mathrm{~kg} / \mathrm{m}^{3}$, -9.51 to $-35.83 \mathrm{~kg} / \mathrm{m}^{3},-2.20$ to $-85.01 \mathrm{~kg} / \mathrm{m}^{3}$, and -27.99 to $-72.91 \mathrm{~kg} / \mathrm{m}^{3}$ respectively for black soil, silt loess, clay loess, and purple soil under the total volume of sediment-laden water of $50 \mathrm{~L}$, and their corresponding values were -139.72 to $-319.95 \mathrm{~kg} / \mathrm{m}^{3}$, -99.90 to $-120.86 \mathrm{~kg} / \mathrm{m}^{3},-14.85$ to $-81.46 \mathrm{~kg} / \mathrm{m}^{3}$, and -52.46 to $-113.23 \mathrm{~kg} / \mathrm{m}^{3}$ under the total volume of sediment-laden water of $100 \mathrm{~L}$.

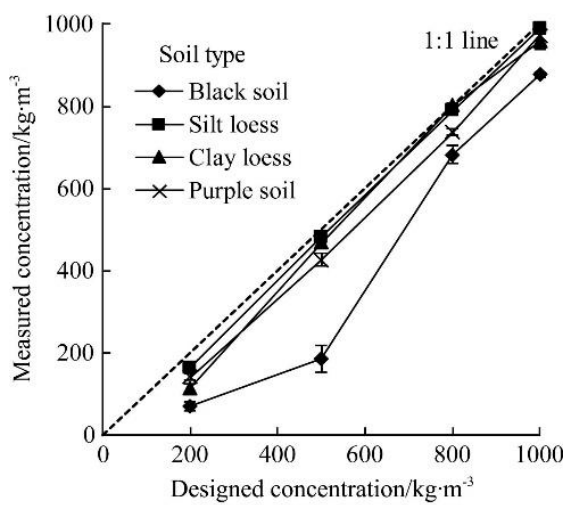

a. $50 \mathrm{~L}$

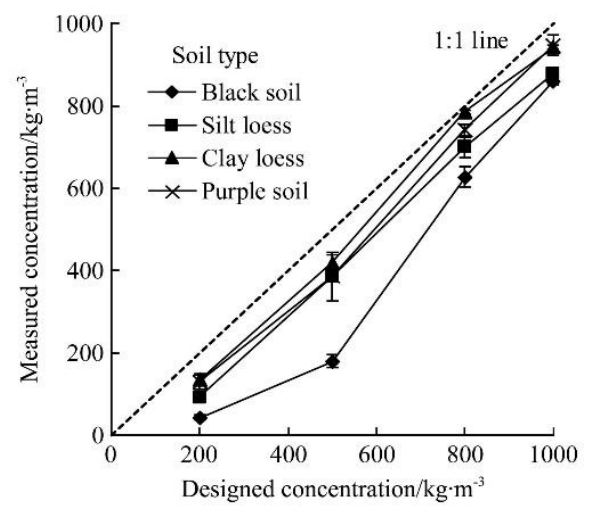

b. $100 \mathrm{~L}$

Figure 5 Comparison of the measured with the designed sediment concentrations in the extremely high sediment concentration group of $200-1000 \mathrm{~kg} / \mathrm{m}^{3}$ for 4 tested soils under total sediment-laden water volume of $50 \mathrm{~L}$ and $100 \mathrm{~L}$

\subsection{Relative error of measured sediment concentrations}

The relative error of measured sediment concentration generally decreased gradually with the increase of designed sediment concentration (data not shown), which means the greater the designed concentration was, the more reliable the measured result was.

\subsubsection{Low sediment concentration group}

The relative error of sediment concentration measurement in the low concentration group of $1-20 \mathrm{~kg} / \mathrm{m}^{3}$ are shown in Figure 6 for four soils. The relative error increased rapidly firstly and then decreased gradually with the increase of designed sediment concentrations (Figure 6). The relative error for black soil was greatest, and that of silt loess was smallest in all four tested soils. The relative errors for clay loess and purple soil were similar to each other, and they were smaller than black soil but bigger than silt loess (Figure 6). A bigger volume of sediment-laden water resulted in a greater relative error (Figure 6). The mean relative error in the low sediment concentration group was $68.5 \%, 29.9 \%$, $42.6 \%$, and $42.8 \%$ respectively for black soil, silt loess, clay loess, and purple soil under total sediment-laden water volume of $50 \mathrm{~L}$, and its corresponding value was $75.9 \%, 42.5 \%, 58.0 \%$, and $56.5 \%$ under the volume of $100 \mathrm{~L}$.

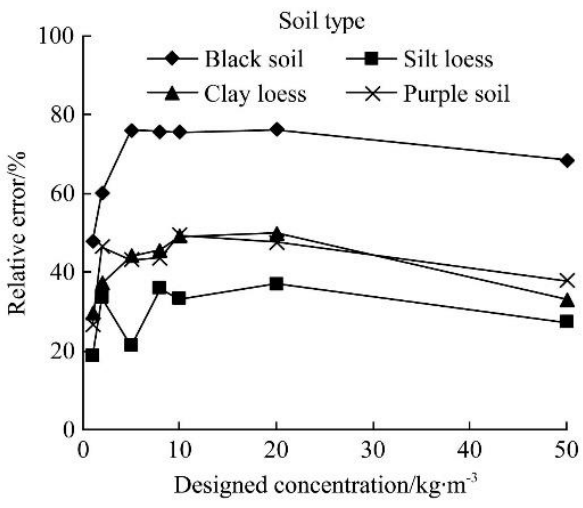

a. $50 \mathrm{~L}$

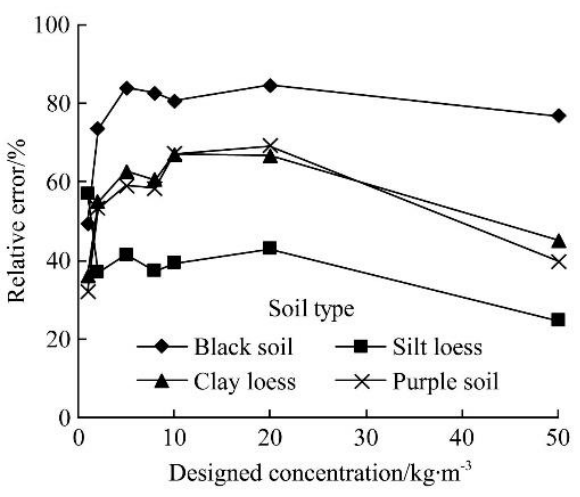

b. $100 \mathrm{~L}$

Figure 6 Relative errors of measured sediment concentrations at the low sediment concentration group of $1-50 \mathrm{~kg} / \mathrm{m}^{3}$ for 4 tested soils under total sediment-laden water volume of $50 \mathrm{~L}$ and $100 \mathrm{~L}$

\subsubsection{High sediment concentration group}

The relative errors in the high sediment concentration group of $50 \mathrm{~kg} / \mathrm{m}^{3}$ to $200 \mathrm{~kg} / \mathrm{m}^{3}$ are shown in Figure 7 for four tested soils. The relative errors in the concentration range tended to be steady with the variation of designed sediment concentrations for four tested soils (Figure 7). The relative error for black soil was significantly greater than other soils that had a similar relative error value (Figure 7). A bigger sediment-laden water volume also resulted in a greater relative but the volume effect on clay loess and purple soil was little (Figure 7). The mean relative error in the high sediment concentration group was $65.2 \%, 24.8 \%, 32.1 \%$, and $34.3 \%$ respectively for black soil, silt loess, clay loess, and purple soil under total sediment-laden water volume of $50 \mathrm{~L}$, and its corresponding value was $76.3 \%, 35.4 \%, 37.0 \%$, and $35.0 \%$ under the volume of $100 \mathrm{~L}$.

\subsubsection{Extremely high sediment concentration group}

The relative error in the extremely high concentration group of $500-1000 \mathrm{~kg} / \mathrm{m}^{3}$ generally decreased with the increased sediment concentration (Figure 8). As the high concentration group, the relative error for black soil was greater than the other soils, and a bigger sediment-laden water volume resulted in a greater relative error (Figure 8). The mean relative error in the extremely high sediment concentration group was $38.6 \%, 5.9 \%, 13.3 \%$, and $13.6 \%$ respectively for black soil, silt loess, clay loess, and purple soil under total sediment-laden water volume of $50 \mathrm{~L}$, and its corresponding value was $44.5 \%, 25.2 \%, 30.1 \%$, and $16.2 \%$ under the volume of $100 \mathrm{~L}$. 


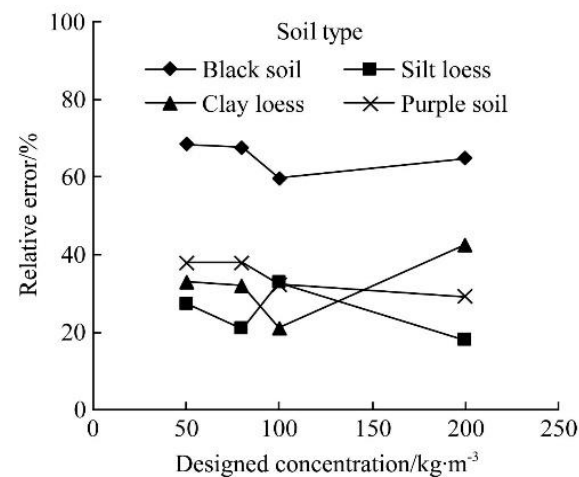

a. $50 \mathrm{~L}$

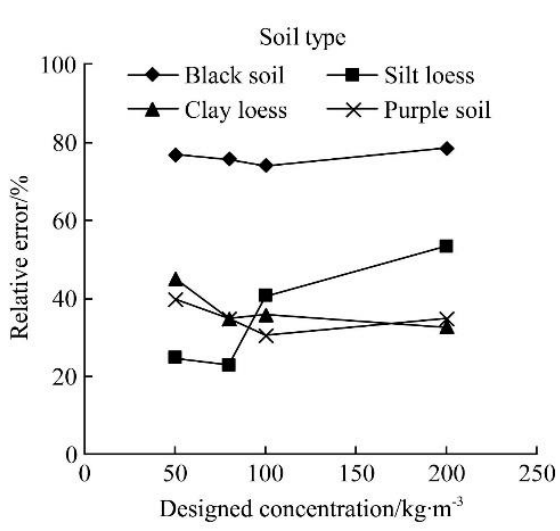

b. $100 \mathrm{~L}$

Figure 7 Relative errors of measured sediment concentrations at the high sediment concentration group of $50-200 \mathrm{~kg} / \mathrm{m}^{3}$ for four tested soils under total sediment-laden water volume of $50 \mathrm{~L}$ and $100 \mathrm{~L}$

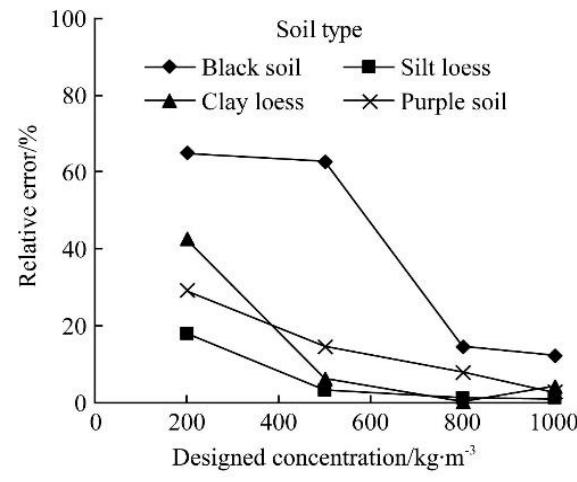

a. $50 \mathrm{~L}$

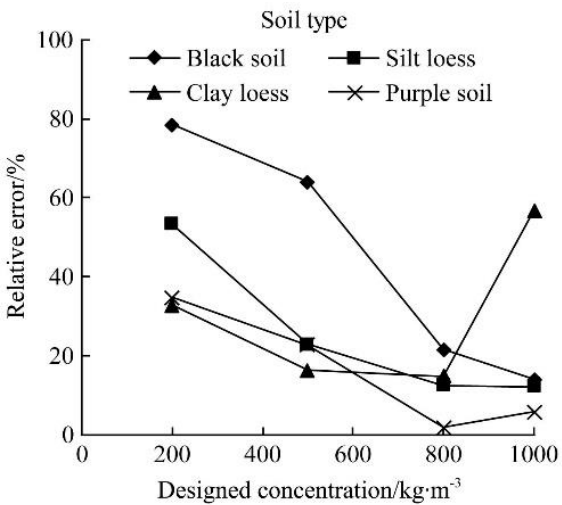

b. $100 \mathrm{~L}$

Figure 8 Relative errors of measured sediment concentrations at the extremely high sediment concentration group of $200-1000 \mathrm{~kg} / \mathrm{m}^{3}$ for four tested soils under total sediment-laden water volume of $50 \mathrm{~L}$ and $100 \mathrm{~L}$

\section{Discussion}

\subsection{Measurement deviation and its correction}

In the whole range of tested sediment concentrations, the measured concentration always was smaller than its designed value (Figures 3-5). Therefore, there existed a systematic measurement error for the stirring-sampling method. The error source maybe derives from the soil particle deposition within the interval from stirring to sampling processes. Though the time interval is short, some big soil particles settle down rapidly to the lower part of collection tank after stirring, and this necessarily decreases the sediment concentration in samples. Soil particle content in water affects its settling velocity ${ }^{[31]}$ and denser sediment-laden water usually results in a relative slow deposition of soil particle and more sediments were easily sampled, which possibly is the reason of different systematic errors for different sediment concentration ranges (Figures 3-5). Generally, sediment concentration exerts an obvious effect on the reliability of measurement result. Despite a great absolute difference between the measured and the designed values, a more accurate and reliable measurement value generally can be obtained when sediment concentration is greater (Figures 6-8). Although there existed an obvious deviation between measured and its true value, the good linearly correlation between the measured and the designed concentrations in the different concentration group demonstrates the systematic measurement error caused by traditional stirring-sampling method can be corrected by the piecewise fitting method.

\subsection{Effects of soil type}

Soil property is the main influence factor for the measurement error of sediment concentration. The sediment-laden water on the upper part of collection tank was vigorously stirred but that on the lower part was less stirred, which results in less coarse particles being sampled. In additions, the coarse particle is rapidly sunk down to the bottom of collection tank, and it cannot be easily sampled. According to Stokes' rule ${ }^{[32]}$, the settling velocity of 0.5 $\mathrm{mm}$ particles is 6 times as fast as that of $0.2 \mathrm{~mm}$ particle. This maybe is one reason of the measured concentrations smaller than the designed concentrations. Our experimental results showed that black soil resulted in a greater measurement error than the other soil (Figures 3-8), which may indicate a more important soil characteristic affecting sediment concentration measurement accuracy, that is, soil aggregate water stability, other than soil texture. There are richer organic matters in black soil ${ }^{[33]}$ and its aggregate is more stable ${ }^{[34]}$ as compared with other three soils, so fast sediment deposition may easily occurr even during the stirring process. Therefore, to develop a specific fitted equation for different soils is needed to accurately correct the measurement error of traditional stirring-sampling method.

\subsection{Sediment-laden water volume}

The total volume of sediment-laden water involves in stirring uniformity and sampling representative. The bigger the water volume is, the difficult the stirring process is, and hence the worse the stirring uniformity is. Moreover, sediment concentration is uneven along with the vertical profile, and it is greater in the lower part of collection tank and smaller in the upper part due to soil particle deposition. The same sampling location at the $15-20 \mathrm{~cm}$ depth in this experiment means that the sediment mass collected in a bigger water volume is smaller than that in a smaller one. Both reasons maybe resulted in greater measurement errors in the big volume of sediment-laden water than that in the small one (Figures 3-5). 


\section{Conclusions}

Stirring-sampling method is a traditional technique to measure sediment concentration in runoff collection tank, but its measured concentration was usually smaller than the designed due to coarse soil particle deposition during stirring-sampling process. In whole tested sediment concentration range, the systematic errors were -0.48 to $-313.57 \mathrm{~kg} / \mathrm{m}^{3},-0.19$ to $-35.83 \mathrm{~kg} / \mathrm{m}^{3},-0.30$ to $-85.01 \mathrm{~kg} / \mathrm{m}^{3}$, and -0.27 to $-72.91 \mathrm{~kg} / \mathrm{m}^{3}$ respectively for black soil, silt loess, clay loess, and purple soil under the total sediment-laden water volume of $50 \mathrm{~L}$, and their corresponding values were -0.49 to $-319.95,-0.57$ to $-120.86,-0.36$ to -81.46 , and -0.32 to -113.23 $\mathrm{kg} / \mathrm{m}^{3}$ under the total sediment-laden water volume of $100 \mathrm{~L}$. The relative errors were $12.3 \%-76.1 \%, 1.0 \%-37.0 \%, 0.3 \%-49.9 \%$, and $2.8 \%-49.4 \%$ respectively for black soil, silt loess, clay loess, and purple soil under the total sediment-laden water volume of $50 \mathrm{~L}$, and their corresponding values were $14.0 \%-84.5 \%, 12.1 \%-57.0 \%$, $14.9 \%-66.9 \%$, and $1.9 \%-69.1 \%$ under the total volume of $100 \mathrm{~L}$.

Though relative great measurement errors existed, the measured concentration values of all four tested soils were well correlated to the designed sediment concentration at a statistically significant level within the segmented concentration range, therefore the systematic error of sediment concentration measurement caused by traditional stirring-sampling method can be corrected by the piecewise linear fitting equation. This experimental result affirms that the traditional stirring-sampling procedure on sediment concentration measurement is feasible in practical application and more accurate measurement result is obtainable by correction of fitting formula.

\section{Acknowledgements}

This work was financially supported by the "National Key Research and Development Program of China" under Project No. 2016YFC0502403, and the "National Natural Science Foundation of China" under Project No. 41230746 and No. 51621061.

\section{[References]}

[1] Xu F, Guo H D, Guo S Y. Preliminary discuss on soil and water conservation monitoring in China. Journal of Soil and Water Conservation, 2001; 15(6): 1-5. (in Chinese)

[2] Li Z G, Jiang X B, Liu E J, Zhao $\mathrm{H}$. Present status and future development of technologies and methods for soil and water conservation monitoring in China. Science of Soil and Water Conservation, 2015; 13(4): 144-148. (in Chinese)

[3] Muteliler C K. Runoff plot design and installation for soil erosion studies. Agricultural Research Service, U.S. Department of Agriculture, Washington, D.C., 1963; pp.41-79.

[4] Meyer L D, Harmon W C. Multiple-intensity rainfall simulator for erosion research on row side slopes. Transactions of ASAE, 1979; 22(1): 100-103

[5] Meyer L D. Evolution of the universal soil loss equation. Journal of Soil \& Water Conservation, 1984; 39(2): 99-104.

[6] Guo S Y, Li Z G. Development and achievements of soil and water conservation monitoring in China. Science of Soil and Water Conservation, 2009; 7(5): 19-24. (in Chinese).

[7] Wischmeier W H, Smith D D. Predicting rainfall erosion losses from cropland east of the rocky mountains. Agricultural Handbook No. 282. US Dept Agric. Washington, DC, 1965.

[8] Edwards K, Rosewell C J. Evaluation of alternative land management and cropping practices for soil conservation. Soil Use and Management, 1990; 6: 120-124.

[9] Hudson N W. Field Measurement of Soil Erosion and Runoff. Soils Bulletin, 1993; 68: 139

[10] Flanagan D C, Nearing M A. Sediment particle sorting on hillslope profiles in the WEPP model. Transactions of ASAE, 2000; 43(3):
573-583.

[11] Mohamadi M A, Kavian A. Effects of rainfall patterns on runoff and soil erosion in field plots. International Soil \&Water Conservation Research, 2015; 3: 273-281.

[12] Vaezi A R, Hasanzadah H, Cerdà A. Developing an erodibility triangle for soil textures in semi-arid regions, NW Iran. Catena, 2016; 142: 221-232.

[13] Strohmeier S, Laaha G, Holzmann H, Klik A. Magnitude and occurrence probability of soil loss: A risk analytical approach for the plot scale for two sites in lower Austria. Land Degradation \& Development, 2016; 27: 43-51.

[14] Lu B J, Yuan A P, Zhang W B. Quickly measuring method of sediment concentration in collecting tanks of runoff plots. Bulletin of Soil and Water Conservation, 2009; 29(2): 15-17. (in Chinese)

[15] Wang W T, Yin S Q, Xie Y, Liu B Y, Liu Y N. Effects of four storm patterns on soil loss from five soils under natural rainfall. Catena, 2016; 141: 56-65.

[16] Ye Z H, Liu B Y, Lu B J, Zeng X Q, Fu S H. Design and testing of the depth profile sediment sampler for runoff plots. Journal of Sediment Research, 2005; 3: 24-29. (in Chinese)

[17] Nikkami D. Investigating sampling accuracy to estimate sediment concentrations in erosion plot tanks. Turkish Journal of Agriculture and Forestry, 2012; 36: 583-590.

[18] Carollo F G, Di Stefano C, Ferro V, Pampalone V, Sanzone F. Testing a new sampler for measuring plot soil loss. Earth Surface Process and Landforms, 2016; 41(7): 867-874.

[19] Kinnell P I A. The effect of kinetic energy of excess rainfall on soil loss from non-vegetated plots. Australian Journal of Soil Research, 1983; 21: 445-454.

[20] Lang R D. Accuracy of two sampling methods used to estimate sediment concentrations in runoff from soil-loss plots. Earth Surface Processes and Landforms, 1992; 17: 841-844.

[21] Villatoro-Sánchez M, Le Bissonnais Y, Moussa R, Rapidel B. Temporal dynamics of runoff and soil loss on a plot scale under a coffee plantation on steep soil (Ultisol), Costa Rica. Journal of Hydrology, 2015; 523: 409-426.

[22] Bagarello V, Ferro V. Calibrating storage tanks for soil erosion measurement from plots. Earth Surface Process and Landforms, 1998; 23 : 1151-1170.

[23] Fu S H, Fu J S, Wang X L, Liu B Y, Yuan A P. Sediment content measurement in collecting tanks of runoff plots. Bulletin of Soil and Water Conservation, 2003; 23(6): 39-41. (in Chinese)

[24] Todisco F, Vergni L, Mannocchi F, Bomba C. Calibration of the soil loss measurement method at the Masse experimental station. Catena, 2012;91: $4-9$.

[25] Xu Y H, Wang H, Tang P, Zhang Y X, Liao X C. Study of the sampling method for sediment content measurement in the runoff plots. Subtropical Soil and Water Conservation, 2014; 26(3): 5-7 and 65. (in Chinese)

[26] Zöbisch M A, Klingspor P, Oduor A R. The accuracy of manual runoff and sediment sampling from erosion plots. Journal of Soil \& Water Conservation, 1996; 51: 231-233.

[27] Ciesiolka C A A, Yu B F, Rose C W, Ghadiri H, Lang D, Rosewell C. Improvement in soil loss estimation in USLE type experiments. Journal of Soil \& Water Conservation, 2006; 61: 223-229.

[28] Wu L, Liu X, Ma X Y. Tracking soil erosion changes in an easily-eroded watershed of the Chinese Loess Plateau. Polish Journal of Environmental Studies, 2016; 25(1): 332-344.

[29] Wu L, Jiang J, Li G X, Ma X Y. Characteristics of pulsed runoff erosion events under typical rainstorms in a small watershed on the Loess Plateau of China. Scientific Reports, 2018; 8: 3672.

[30] SL277-2002. Technical code of practice on water and soil conservation monitoring. Beijing: China Water Power Press, 2002. (in Chinese)

[31] Dietrich W E. Settling velocity of natural particles. Water Resources Research, 1982; 18(6): 1615-1626.

[32] Gomboš M, Tall A, Trpčevská J, Kandra B, Pavelkova D, Balejčíková L. Sedimentation rate of soil microparticles. Arabian Journal of Geosciences, 2018; 11: 635 .

[33] Yang X Y, Chen X W, Yang X T. Effect of organic matter on phosphorus adsorption and desorption in a black soil from Northeast China. Soil \& Tillage Research, 2019; 187: 85-91.

[34] Gao X, Hu Y X, Sun Q Q, Du L L, Duan P F, Yao L G, Guo S L. Erosion-induced carbon losses and $\mathrm{CO}_{2}$ emissions from Loess and Black soil in China. Catena, 2018; 171: 533-540. 